\title{
COMERCIALIZAÇÃO DE INOVAÇÕES: UMA ANÁLISE DOS PROBLEMAS ENFRENTADOS POR PEQUENAS EMPRESAS DE BASE TECNOLÓGICA GRADUADAS EM UMA INCUBADORA BRASILEIRA
}

Rodrigo Lacerda Sales ${ }^{1}$

Francisco José De Castro Moura Duarte ${ }^{2}$

Anne-Marie Maculan ${ }^{3}$

\footnotetext{
${ }^{1}$ Centro Federal de Educação Tecnológica de Minas Gerais

${ }^{2}$ Programa de Engenharia de Produção / Coppe / Universidade Federal do Rio de Janeiro

${ }^{3}$ Universidade Federal do Rio de Janeiro
} 


\section{COMERCIALIZAÇÃO DE INOVAÇÕES: UMA ANÁLISE DOS PROBELMAS ENFRENTADOS POR PEQUENAS EMPRESAS DE BASE TECNOLÓGICA GRADUADAS EM UMA INCUBADORA BRASILEIRA}

\section{Resumo}

Esta pesquisa teve como objetivo principal identificar as especificidades dos problemas de comercialização das inovações de dez pequenas empresas de base tecnológica - PEBTs graduadas em incubadora brasileira. As questões centrais do estudo foram: Quais as principais dificuldades as PEBTs enfrentam na hora de oferecer seus novos produtos e serviços ao mercado? Que razões estão na origem dessas dificuldades? Os resultados apontaram que as PEBTs passam por algumas dificuldades ao comercializarem suas inovações por duas razões principais: (1) excessiva concentração dos esforços de venda nos empreendedores e contatos com os clientes realizados tardiamente, (2) não desenvolveram e construíram competência em comercialização, especificamente identificando um nicho de mercado e considerando os clientes iniciais e potenciais para poder desenvolver um modelo de negócio viável, usando suas redes de contatos efetivamente.

Palavras-Chaves: pequenas empresas de base tecnológica. comercialização. inovação.

\section{INTRODUÇÃO}

No ambiente de negócios, a competitividade está fortemente dependente da capacidade das empresas para criar e explorar efetivamente suas inovações. Nesse contexto, as PEBTs pequenas empresas consideradas como de base tecnológica e que geralmente passam por um processo de incubação, recebem apoio de agentes de inovação, universidades e institutos de pesquisa, ciência e tecnologia, podem exercer um importante papel contribuindo com a geração de emprego e com o desenvolvimento econômico. Por isso, no Brasil, esses empreendimentos são hoje objeto de políticas públicas.

De acordo com o relatório "Estudo, Análise e Proposições sobre as Incubadoras de Empresas no Brasil" publicado pela ANPROTEC (2012), as 384 incubadoras associadas à ANPROTEC (63\% dessas incubadoras foram classificadas como tecnológica e mista em 2005) foram, nesse período, responsáveis por 2.509 empresas graduadas, que faturam $\mathrm{R} \$ 4,1$ bilhões anuais e empregam 29.205 pessoas (média de 11,92 empregos), sendo que as empresas incubadas somam 2.640 com 16.394 postos de trabalho (média de 6,21 empregos) e faturamento de $\mathrm{R} \$$ 533 milhões.

Ainda de acordo com o estudo da ANPROTEC (2012), a taxa de insucesso das PEBTs é inferior à dos negócios de setores tradicionais. Apesar disso, esses empreendimentos, de forma geral, apresentam várias limitações ao seu crescimento, empregando um número reduzido de pessoas

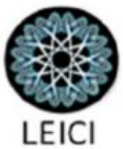


e apresentando baixo crescimento de vendas, ou seja, os negócios sobrevivem, mas não crescem (SANTOS e PINHO, 2010; FERNANDES, CORTES e PINHO, 2004 e PINHO, CÔRTES e FERNANDES, 2002).

A revisão da literatura apresentada neste trabalho evidencia que as PEBTs têm várias limitações ao seu crescimento e que uma das principais causas dessas limitações está diretamente relacionada aos problemas enfrentados na comercialização de suas inovações.

Nesse contexto, é importante analisar as experiências das PEBTs graduadas ${ }^{1}$ para identificar os fatores, obstáculos e limitações que impedem o crescimento de suas vendas e a relação desses fatores com os problemas na comercialização de suas inovações.

Esta pesquisa limitará seu foco de estudo nas PEBTs graduadas na Incubadora de Base Tecnológica da Universidade Federal de Viçosa - IBT/UFV. Tal limitação se justifica por dois motivos: (1) Natureza das PEBTs: as incubadoras de base tecnológica geralmente têm como premissas em seus editais de seleção que somente poderão participar dos processos seletivos empresas com projetos que possuam características inovadoras com possibilidades de ter viabilidade econômica, financeira e comercial, (2) Fase de maturidade do negócio: empresas que passaram por um processo de incubação, se graduaram e se encontram no mercado há mais de cinco anos, já podem ter adquirido experiência e know how, em relação às suas práticas de comercialização e superado os obstáculos e limitações em relação á comercialização de suas inovações.

Além disso, para identificar se as PEBTs realmente introduziram no mercado produtos ou serviços inovadores, foram considerados na seleção da amostra três elementos, são eles: (1) Propriedade Intelectual (especificamente patentes e registro de software); (2) Investimentos em P\&D e (3) Captação de recursos em Agências de Fomento para o desenvolvimento das tecnologias introduzidas no mercado. Foram selecionadas dez PEBTs que tiveram pelo menos dois desses elementos ao longo de sua trajetória.

Empresas de base tecnológica e de pequeno porte diferem das grandes empresas em muitos aspectos relacionados com a inovação. Essas empresas geralmente têm estratégias de entrada no mercado relativamente limitadas, poucos recursos financeiros para desenvolvê-las e carecem de habilidades em gestão e formulação de estratégia de comercialização (PELLIKKA, 2014; FORSMAN, 2011; LIAO e RICE, 2010; de JONG e MARSILI, 2006; FREEL, 2005; WONGLIMPIYARAT e YUBERK, 2005; FORSMAN, 2011; ANDRADE, 2012 e D'AVINO et. al. 2015). A estrutura e os processos de pequenas empresas são relativamente informais, e, em geral, os objetivos de negócios e as estratégias relacionadas não são muito claros, devido à limitada experiência dos dirigentes em gestão e implementação de atividades destinadas a comercializar os produtos (PELLIKKA e PELLIKKA, 2011; PELIKKA e MALINEN, 2014 e 2015; HANG DO, 2014 e COKINDALE, 2010). Nesse contexto, é possível apontar para as seguintes questões de pesquisa:

(1) Quais as principais dificuldades as PEBTs enfrentam na hora de oferecer seus novos

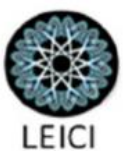


produtos e serviços ao mercado? (2) Que razões estão na origem dessas dificuldades? (3) Qual o papel da incubadora no apoio à comercialização das inovações ao longo do período de incubação? A pesquisa tem como objetivo principal identificar as especificidades dos problemas de comercialização das inovações pelas PEBTs graduadas e as soluções aplicadas por essas empresas para introduzir as inovações desenvolvidas no mercado.

\section{REFERENCIAL TEÓRICO}

\subsection{COMERCIALIZAÇÃO DE INOVAÇÕES}

Ao realizarem uma revisão de literatura sobre áreas-chave de pesquisa com foco em gestão da inovação, Adams, Bessant e Phelps (2006) identificaram que existem lacunas significativas, particularmente no campo da comercialização. Os autores destacam sete áreas sobre a medição da gestão da inovação: 1) inputs - pessoas, recursos físicos e financeiros, ferramentas; 2) gestão do conhecimento - geração de ideias, repositório de conhecimentos, fluxos de informação; 3 ) estratégia de inovação - orientação estratégica, liderança estratégica; 4) organização e cultura cultura, estrutura; 5) gestão de portfólio - equilíbrio risco / retorno, uso de ferramentas de otimização; 6) gerenciamento de projetos - eficiência do projeto, ferramentas, comunicações, colaboração; e 6) comercialização - pesquisa de mercado, testes de mercado, marketing e vendas.

Para esses autores, o processo de comercialização está relacionado às capacidades de marketing da empresa, tais como pesquisa de mercado, promoção, planejamento e monitoramento de mercado a fim de lançar os produtos ou serviços.

Nesta direção, Moore (2002) enfatizou o significado da orientação para o mercado e as dificuldades das empresa para identificar o segmento de mercado inicial e a abordagem que será adotada na comercialização de inovações.

A comercialização é o resultado final do longo processo de uma estratégia de inovação, cujos elementos e complexidade vão se afunilando ao longo da gestão da inovação (MAZZAROL, REBOUD e SOUTAR, 2011).

De acordo com Zahra e Nielsen (2002), a comercialização é o processo através do qual as empresas criam valor econômico por meio da transformação e incorporação de conhecimentos, descobertas e invenções, em produtos e serviços novos ou significativamente melhorados para atender a demandas dos compradores e consumidores no mercado.

A definição de comercialização de inovações de Datta, Red e Jessup (2013) tem três elementos constitutivos: (1) o reconhecimento de um mercado para uma inovação; (2) desenvolvimento e fabricação de um produto e (3) a venda / distribuição do produto.

O primeiro elemento é endereçado através dos temas de fontes de inovação, bem como tipos de inovação e proteção. Os dois últimos são essencialmente abordados através de entrada no mercado, desenvolvimento e implantação. Os autores desmentem a ideia de que a 
comercialização de inovação é uma construção simples. Argumentam que são várias as definições, conceituações e operacionalizações que surgem dos estudos publicados.

\subsection{PROBLEMAS NA COMERCIALIZAÇÃO DE INOVAÇÕES}

De acordo com Pellikka e Virtanen (2009) e (Kajanus, et. al. 2011), estudos anteriores sugerem que as principais áreas problemáticas no processo de comercialização são: (1) Ambiente de comercialização: A disponibilidade de recursos qualificados, infraestrutura adequada, a existência de serviços de apoio e desenvolvimento e redes de negócios; (2) Financiamento: o capital insuficiente, problemas de fluxo de caixa, e os problemas no controle de margens / lucros e despesas; (3) Gestão: desenvolvimento de competências organizacionais e de alocação de recursos. Deixar de definir metas de comercialização, falta de colaboração e parcerias para comercializar P\&D e a falta de explorar as oportunidades de mercado de forma rápida e (4) Marketing: Aquisição de informações de mercado (as empresas não conseguem entender o potencial de mercado real e as necessidades de seu mercado e clientes).

Freel (2005) também dá destaque sobre a aptidão das pequenas empresas para a inovação e aponta consistentemente para a onipresença das habilidades de gestão insuficientes e, mais precisamente, as habilidades de marketing insuficientes. Para esse autor, as deficiências de gestão dentro das pequenas empresas incluem entre outras coisas: (1) uma má avaliação do planeamento financeira (que conduz a uma subestimação sistemática dos custos de comercialização e de desenvolvimento do produto); (2) delegação inadequada; (3) falta de experiência e / ou apoio funcional; (3) descontinuidade do pessoal de gestão; (4) esforços de marketing insuficientes e (5) dependência de vendas ad hoc ou boca-a-boca.

Os empreendedores de startups geralmente têm pouca experiência e poucas informações sobre o mercado onde vão tentar comercializar devido à juventude e tamanho pequeno dessas empresas,. Eles dispõem de, no máximo, duas ou três tecnologias (produtos ou serviços) na fase de potencial introdução no mercado. Segundo os autores, para essas empresas, o principal desafio de gestão é traduzir a comercialização de produtos baseados em tecnologias promissoras em fluxo de retorno econômico para empreendedores, investidores e funcionários. Em outras palavras, o problema principal não é tanto a inovação, mas a comercialização (GANS e STERN, 2003).

A comercialização é uma fase crítica do processo de inovação tecnológica, principalmente por causa dos altos riscos, custos e das incertezas que ela implica. Muitas vezes é a fase que acarreta mais problemas de gestão em todo o processo de inovação (COSTA, FONTES e HEITOR, 2004; PELLIKKA e VIRTANEN, 2009 e CHIESA e FRATTINI, 2011). 
Aarikka-Stenroos e Sandberg (2012) consideram que a comercialização de um produto parece ser mais complicada do que a literatura retrata e mostram como vários atores, com uso de diversos recursos, executam tarefas e atividades cruciais de comercialização e, dessa maneira, conseguem reduzir a resistência à novidade por parte dos compradores.

Pellikka e Virtanen (2009), argumentam que a comercialização das inovações pelas PEBTs é um processo de extrema importância. Para organizá-lo os gestores dessas empresas devem: (1) adquirir competências complementares e alocar recursos suficientes em marketing e internacionalização dos negócios; (2) os capitalistas de risco devem cuidar dessa experiência e capacidades em marketing e internacionalização, (3) os decisores políticos devem garantir a disponibilidade de recursos humanos qualificados na área (isso requer a organização do sistema de ensino e de gestão de recursos humanos) para atender às necessidades das pequenas empresas de base tecnológica e (4) as universidades e instituições de ensino devem educar e qualificar recursos humanos para as empresas localizadas em seu entorno.

\section{METODOLOGIA}

Devido às características da pesquisa, e à busca de um entendimento aprofundado e detalhado das especificidades dos problemas relacionados à comercialização das inovações pelas PEBTs, bem como das práticas adotadas para superá-los, optou-se por fazer uma pesquisa exploratóriodescritiva, com uma abordagem metodológica qualitativa, na qual se buscou a identificação e explicação sistemática de fatos que ocorrem num contexto social, geralmente relacionado a uma multiplicidade de variáveis (GIL, 2006).

Para analisar os fatos do ponto de vista empírico optou-se pelo método estudo de casos múltiplos que, segundo Eisenhardt e Graebner (2007) e Yin (2010), significa fazer uma pesquisa empírica visando investigar um fenômeno contemporâneo dentro do seu contexto real, de forma especial quando os limites entre o fenômeno e o contexto não estão claramente definidos. Para esses autores, a descoberta do "como" e do "por que" determinam o que se deseja responder na pesquisa.

Para atingir os objetivos propostos nesta pesquisa, selecionou-se as seguintes fontes de evidências: (1) Dados Primários: entrevistas com pelo um dos empreendedores fundadores da empresa (sócio-gerente), gestor administrativo ou comercial de cada PEBT graduada; (2) Dados secundários: informações públicas sobre a empresa e seu setor de atuação (sites, notícias na mídia, relatórios técnicos, matérias em revistas especializadas etc.) e, em alguns casos, análise de documentos como o Plano de Negócio apresentado pelas empresas quando participaram do processo seletivo da incubadora e (3) Observações da estrutura organizacional da empresa, bem como dos mapas destacando as regiões de atuação, dos quadros de aviso com agenda de atividades e anotações da área comercial (quando existentes). Tais observações foram feitas durante as visitas às dez empresas.

Este estudo analisa as práticas das Pequenas Empresas de Base Tecnológica - PEBTs graduadas na Incubadora de Base Tecnológica da Universidade Federal de Viçosa - IBT/CENTEV de 
1996 (início de suas atividades) a Maio de 2015. Das vinte e nove empresas graduadas até 2015, quatro já tinham encerrado as atividades no momento da pesquisa e quatro não retornaram o primeiro contato. Das vinte e uma empresas possíveis, quatorze autorizaram a realização da pesquisa e o agendamento da visita e entrevista. Dessas, três não forneceram as informações sobre o histórico de faturamento do negócio e uma não se enquadrou na delimitação do estudo.

As entrevistas ocorreram entre os meses de agosto de outubro de 2015. Foram realizadas diretamente com os empreendedores (em oito casos) e com o gerente administrativo (em dois casos). Foram divididas em três etapas. Na primeira, o entrevistado narrava o histórico da criação da empresa, na segunda etapa respondia as perguntas do roteiro de entrevista semiestruturado desenvolvido com base no marco conceitual e na terceira e última etapa respondia a perguntas baseadas num conjunto de informações públicas da empresa. Nesta ultima fase, foram apresentadas algumas perguntas especificas baseadas em observações feitas quando das visitas às empresas. O tempo de duração das entrevistas foi de duas horas, em média. A fim de manter o anonimato, não são informados os nomes das empresas que parecem como sendo Empresas de 1 a 10. A validação dos resultados aconteceu pessoalmente com o entrevistado, entre os meses de novembro e dezembro de 2016.

\section{RESULTADOS E DISCUSSÃO}

Em relação ao ramo de atividade, das dez empresas pesquisadas, oito são do setor de serviços (sete de TI - Software e consultoria técnica para agronegócio, um biotecnologia) e duas do setor industrial (máquinas e equipamentos, biotecnologia - fertilizantes).

O Gráfico 1, a seguir, apresenta dados consolidados das dez PEBTs. Os dados são referentes a: (1) faturamento acumulado dos últimos seis anos para as empresas E5, E6, E7, E9, E10, E11, dos últimos cinco anos para as empresas E3, E12 e E13 e para os últimos quatro anos para a E4; (2) tempo de existência das empresas; (3) tempo de incubação e (4) tempo de entrada no mercado com a inovação.

Observa-se que das quatro empresas com maior faturamento (E6, E7, E9 e E13), duas entraram no mercado com sua inovação após a graduação na IBT/UFV e as outras duas no ano seguinte, o que pode significar, para esses casos, que não houve influência direta do período de incubação na comercialização da inovação. Esse grupo de empresas possui uma média de dezessete anos de existência e de dois anos de incubação

Nas seis empresas com faturamento menor, em cinco (E3, E4, E5, E10 e E11) a entrada no mercado ocorreu quando as empresas ainda estavam incubadas. Esse grupo de empresas possui uma média de doze anos de existência e de quatro anos de incubação. Esse resultado também pode apontar para a inexistência de influência direta do processo de incubação na comercialização da inovação, pois o faturamento dessas empresas foi muito abaixo da média das empresas graduadas em Minas Gerais e no Brasil, de acordo com ANPROTEC (2012) e Faria (2015).

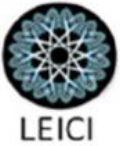


As quatro empresas com maior faturamento tiverem um tempo médio de incubação de dois anos e de entrada no mercado de dois anos e meio. Já as seis empresas de menor faturamento tiveram um tempo médio de incubação de quatro anos e meio e de entrada no mercado de três anos e meio. Ou seja, as empresas de melhor desempenho graduaram e entraram no mercado mais rápido que as de pior desempenho.

\section{Gráfico 1 - Faturamento Acumulado - Tempo de Existência - Tempo de Incubação e Tempo Entrada no Mercado}

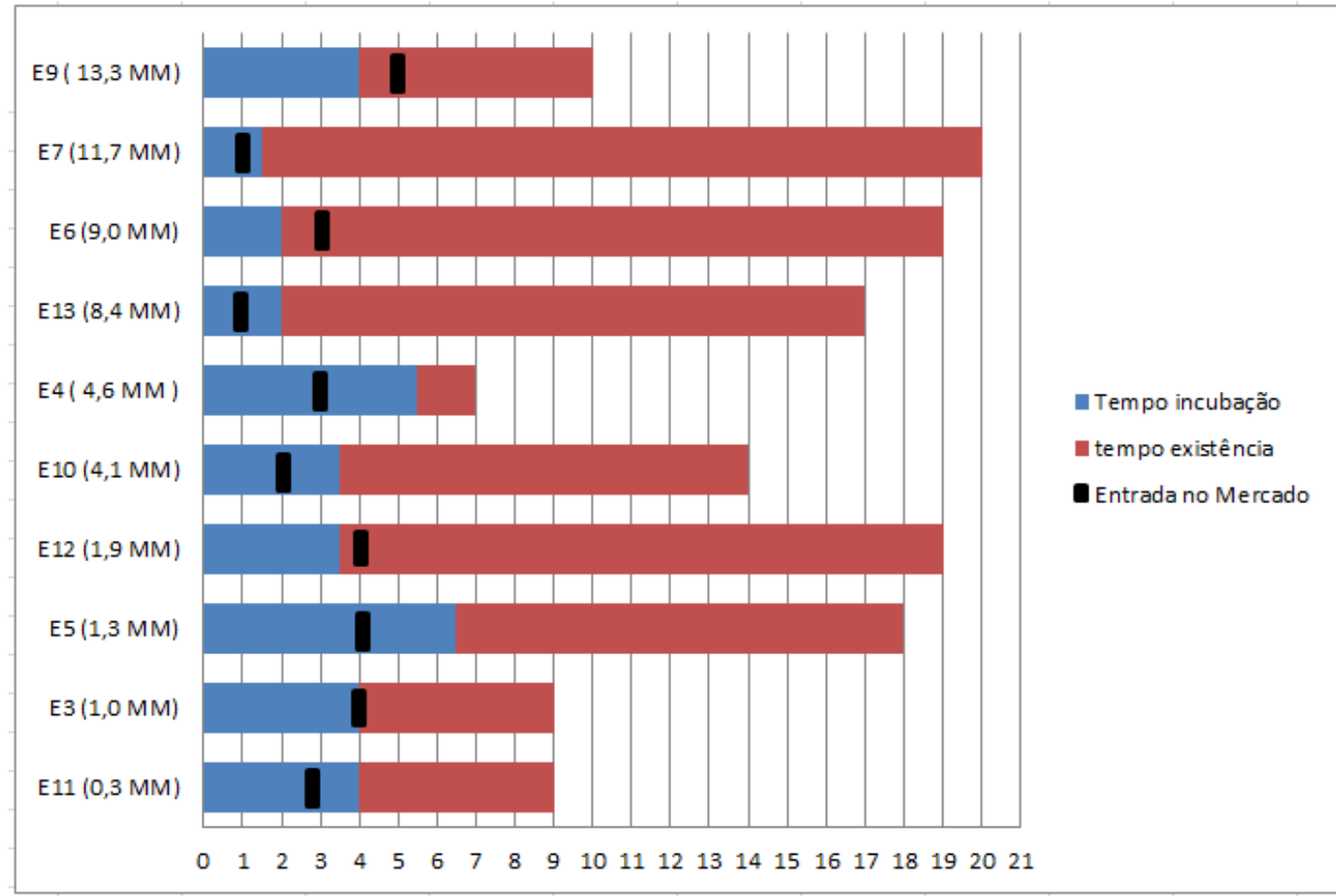

Fonte: Dados da Pesquisa

A média anual de faturamento das empresas no período analisado foi inferior a $\mathrm{R} \$ 250.000,00$ (duzentos e cinquenta mil reais) para três empresas (E3, E5 e E11). Entre esse valor e R\$ 700.000,00 (setecentos mil reais) para duas empresas (E10 e E12). As Empresas 4 e 6 tiveram uma média de entre $\mathrm{R} \$ 700.000,00$ (setecentos mil reais) e $\mathrm{R} \$ 1.600 .000,00$ (um milhão e seiscentos mil). O faturamento médio anual de 2010 a 2015 para E7, E9 e E13 foi em torno de $\mathrm{R} \$ 2.200 .000,00$ (dois milhões e duzentos mil reais).

A titulo de comparação, a média anual de faturamento das empresas graduadas em incubadoras brasileiras foi de $\mathrm{R} \$ 1.600 .000,00 \mathrm{em} 2011$ (ANPROTEC, 2012) e das empresas graduadas em incubadoras do Estado de Minas Gerais foi de R\$ 1.440.000,00 em 2013 (FARIA, 2015). 
Observa-se que apenas a E6, teve média próxima à das empresas graduadas em Minas Gerais e as empresas E7, E9 e E13 tiveram média superior à média dos valores de 2011das empresas graduadas no Brasil e à média dos valores de 2013 das empresas graduadas no Estado de Minas Gerais. No ano de 2013, o valor do faturamento médio dessas empresas foi em torno de $\mathrm{R} \$$ 2.100.000,00, valor 29\% superior aos $\mathrm{R} \$ 1.600 .000,00$ (média de 2011 das empresas graduadas no Brasil) e 54\% superior aos R \$ 1.440.000,00 (média de 2013 das empresas graduadas em Minas Gerais). Das quatro empresas desse Grupo, três são do setor de TI-Software e uma tem a TI-software como base de seus serviços.

Além de representarem as empresas com os maiores faturamentos, as empresas de TI-Software tiveram crescimento superior ao da média do mercado entre 2013 e 2014, sendo que a Empresa 6 cresceu seu faturamento em 24\%, a Empresa 7 cresceu 21\%, a Empresa 9 cresceu 32\% e a Empresa 13, que tem TI como base de seus serviços, cresceu $46 \%$.

De acordo com dados da Associação Brasileira das Empresas de Software (ABES, 2015), esse setor teve um crescimento de $12,8 \%$ neste mesmo período. Portanto, o crescimento do faturamento de todas as empresas de TI pesquisadas no ano de 2014 foi superior ao crescimento do setor de software no Brasil no mesmo período, o que evidencia que essas empresas podem ser consideradas como empresas que crescem acima da média do mercado no qual estão inseridas (MEIRA, 2013).

\subsection{DIFICULDADES, LIMITAÇÕES E SOLUÇÕES APLICADAS PELAS PEBTS}

De forma geral, em todos os casos estudados foi possível identificar que uma das principais dificuldades e limitações enfrentadas pelas PEBTs graduadas está na base de competências em comercialização por parte dos empreendedores. Muitas vezes, a empresa é criada por empreendedores técnicos (empreendedor acadêmico) com uma forte orientação tecnológica e fraca orientação mercadológica e empresarial.

esse é o nosso problema até hoje, ninguém tem visão de negócio...eu também $\mathrm{s} \quad$ ou pesquisadora e aí a gente tem que dar conta de tudo, estou procurando fazer cursos com o SEBRAE para melhorar essa parte. Entrevistado E11

Temos um produto muito bom, mas não estamos sabendo trabalhar isso no mercado, tanto que ele está indo no boca-a-boca...tem anos que a empresa está sempre no mesmo ponto...agora que eu te falo que a empresa está dando uma alavancada muito boa, coisa que nunca aconteceu, de chegar o começo do mês e eu ter dinheiro na conta. Entrevistado E11

eu nunca fui boa em vendas e isso me incomodava. Eu pegar um telefone para ligar para fazer uma venda sempre me incomodou...mas a gente mudou o perfil de ligação, agora elas são mais técnicas, uma consultoria e aí muda tudo, a timidez desaparece, os clientes estão satisfeito e eu também...esse ajuste no como fazer é muito importante. Entrevistada E5 
Os trabalhos de Datta, Red e Jessup (2013), Pellikka e Virtanen (2009), Freel (2005), Forsman (2011), Pellikka e Malinen (2014 e 2015), de Jong e Marsili (2006) e Liao e Rice (2010) destacaram a importância das PEBTs terem tais capacidades e competências em gestão e comercialização das inovações e o papel do treinamento e da formação dos empreendedores na busca pelas capacidades e competências nessas áreas.

Estudo de Freel (2005) também dá destaque sobre a aptidão das pequenas empresas para a inovação e aponta que as habilidades de marketing dos empreendedores dessas empresas são insuficientes. Para esse autor, essas deficiências incluem entre outras coisas: (1) uma má avaliação do planeamento financeira (que conduz a uma subestimação sistemática dos custos de comercialização e de desenvolvimento do produto); (2) delegação inadequada; (3) falta de experiência e / ou apoio funcional; (3) descontinuidade do pessoal de gestão; (4) esforços de marketing insuficientes e (5) dependência de vendas ad hoc ou boca-a-boca.

Identificou-se que há uma excessiva concentração das atividades de venda e suporte nos sócios das PEBTs pesquisadas. Essas atividades foram realizadas quase que exclusivamente pelos próprios empreendedores (Venda Pessoal). Essa prática foi declarada como eficiente nos trabalhos de Datta, Red e Jessup (2013) e Wonglimpiyarat e Yuberk (2005). Os depoimentos a seguir também evidenciam a importância da "Venda Pessoal", feita pelo próprio empreendedor, e do contato direto com os clientes que trazia credibilidade ao negócio e facilitava a concretização das vendas.

\footnotetext{
“...acredito que a venda pessoal, o contato direto com o cliente a propaganda boca-a-boca feita pelos próprios clientes são as maneiras mais eficientes para vender". Empresa 10

“...eu procurava um laticínio, apresentava a metodologia e pedia aos técnicos do laticínio para agendar uma apresentação aos produtores rurais que forneciam leite ao laticínio...50\% dos convidados participavam e, desses, alguns aderiam à ideia de imediato e contratavam o serviço....após a realização do trabalho e dos resultados apresentados, outros produtores passavam a contratar o serviço...a indicação e o boca-a-boca são muito eficientes para trazer novos clientes, pois você passa credibilidade e ganha a confiança do produtor". Empresa 13
}

Há evidências que os empreendedores das PEBTs foram os responsáveis por praticamente todas as vendas realizadas, tanto nas empresas nas empresas de pior como nas de melhor desempenho. Essa prática foi declarada como eficiente nos trabalhos de Datta, Red e Jessup (2013) e Wonglimpiyarat e Yuberk (2005).

Nos casos das empresas com melhor desempenho, os sócios tinham o conhecimento técnico dos seus produtos e serviços e conseguiam transmitir isso aos clientes no momento das negociações, desde o lançamento da ideia. Isso contribuiu decisivamente para o crescimento das vendas. Observou-se a partir dos depoimentos dos empreendedores desse grupo de empresas que eles procuram vender serviços e soluções ao invés do produto em si. As empresas de TI-Software consideraram também que não vendiam softwares e sim serviços. 
Se por um lado essa prática se mostrou eficiente, pois as vendas aconteciam quando eram feitas dessa forma, por outro, sobrecarregava os empreendedores e limitava o crescimento do negócio, pois à medida que o número de clientes crescia, crescia também a área de atuação e a demanda por suporte e pós-venda (principalmente nos casos em que os diferenciais do negócio foram as tecnologias customizadas e o atendimento personalizado - maioria das PEBTs pesquisadas)

As empresas com melhor desempenho passaram a delegar essas atividades criando setores e equipes específicas para a comercialização. Das cinco empresas desse grupo, duas já implementaram essa prática (E6 e E7 - inclusive com a modelização e formalização dos processos) e duas estão em fase de implementação (E9 e E13). Esses aspecto da delegação das atividades concentradas no empreendedor foram considerados nos trabalhos de Freel (2005) e McAdam e McAdam (2008). Cabe registrar que a criação desse setor comercial foi decisão dos empreendedores e demandou investimentos, que tiveram seus recursos financeiros originados dos lucros das próprias empresas (E6, E7, E9 e E13).

Em relação às competências e habilidades em gestão e em comercialização, dos cinco empreendedores das empresas com pior desempenho, dois deles afirmaram não possuir (Empresas 5 e 11), dois afirmaram que possuem pouca (Empresas 3 e 12) mas buscam aprimorá-las por meio de cursos. Apenas um entrevistado desse grupo afirmou ter competências e habilidades em gestão e em comercialização (Empresa 10). Os trabalhos de Datta, Red e Jessup (2013), Pellikka e Virtanen (2009), Freel (2005), Forsman (2011), Pellikka e Malinen (2014 e 2015), de Jong e Marsili (2006) e Liao e Rice (2010) destacaram a importância das PEBTs terem tais capacidades e competências em gestão e comercialização das inovações e o papel do treinamento e da formação para as PEBTs na busca pelas capacidades e competências nessas áreas.

Há evidências empíricas que um dos principais problemas de comercialização das PEBTs graduadas com menor desempenho está relacionado à falta de recursos financeiros para custear as atividades comerciais e contratar recursos humanos com experiência nessa área. A ausência de um setor comercial ou da própria atuação dos sócios nesta área trouxe muitas dificuldades para as empresas. Não foi possível identificar nesse grupo atividades de análise de mercado, prospecção de novos clientes e número reduzido (ou até inexistente) de canais de venda.

Há evidências empíricas também que as principais soluções desenvolvidas por algumas empresas para minimizar os problemas e dificuldades citadas acima foram a ativação e ampliação da rede de contato com os clientes existentes. Esses clientes fazem indicações de clientes potenciais (marketing boca-a-boca). Essa prática foi identificada desde a Fase de Desenvolvimento da Ideia, os ex-professores dos empreendedores faziam indicações dos primeiros clientes e davam legitimidade à ideia.

\footnotetext{
"A prospecção e os contatos" com os clientes potenciais eram feitos por meio da rede de contato dos sócios, por exemplo: “...a gente vê qual é a instituição que queremos nos aproximar, procuramos quem da nossa rede de contato tem acesso e bom relacionamento e pode nos aproximar dessa instituição, às vezes nossos próprios clientes nos indicam e apresentam outros clientes". Empresa 10
}

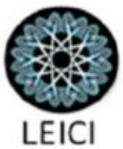


Outra solução aplicada por algumas PEBTs graduadas foi o uso de ferramentas de marketing digital (internet, e-mail marketing, Google, redes sociais).

A Tabela 1 apresenta um resumo dos principais problemas, limitações, dificuldades e barreiras enfrentadas por cada uma das dez PEBTs pesquisadas, bem como as soluções aplicadas por elas para minimizar esses problemas na comercialização de suas inovações ao longo de sua trajetória. 
Tabela 1 - Problemas de Comercialização e Soluções Aplicadas pelas PEBTs Graduadas na IBT/UFV

\begin{tabular}{|c|c|c|}
\hline Empresa & $\begin{array}{c}\text { Problemas: Limitações, Dificuldades e Barreiras enfrentadas na } \\
\text { comercialização }\end{array}$ & $\begin{array}{c}\text { Soluções Aplicadas: Atividades e Práticas de Comercialização } \\
\text { adotadas }\end{array}$ \\
\hline Empresa 3 & $\begin{array}{l}\text { Modelo de negócio instável - dois produtos para mercados totalmente } \\
\text { distintos. } \\
\text { Concentração das atividades de venda e suporte com o sócio } \\
\text { entrevistado, o que acaba limitando o crescimento da empresa. Falta de } \\
\text { recursos humanos em termos de quantidade e qualidade e falta de } \\
\text { recursos financeiros para a contratação desses recursos humanos. }\end{array}$ & $\begin{array}{c}\text { Passaram a atuar somente com um produto em um nicho de mercado } \\
\text { específico, onde identificaram uma necessidade. } \\
\text { Para atrair novos clientes passaram a ampliar a rede de clientes, solicitando } \\
\text { aos clientes atuais que façam indicação de secretarias de assistência social } \\
\text { de outras prefeituras. Ações de marketing digital como e-mail marketing e } \\
\text { redes sociais. }\end{array}$ \\
\hline Empresa 4 & $\begin{array}{l}\text { Falta de recursos financeiros. Falta de recursos humanos } \\
\text { especializados para as atividades comerciais, que pudessem fazer um } \\
\text { trabalho proativo e sistematizado. Problemas na precificação dos } \\
\text { produtos na fase de projeto. Concentração de clientes na áreas pública } \\
\text { trazia instabilidade para o negócio. }\end{array}$ & $\begin{array}{l}\text { Tentavam minimizar essas dificuldades contratando pessoas para a área } \\
\text { comercial, mas perceberam que não atuavam como os sócios e não } \\
\text { atingiam os objetivos propostos. } \\
\text { Contratavam consultorias e treinamentos do SEBRAE. }\end{array}$ \\
\hline Empresa 5 & $\begin{array}{l}\text { Sócios eram pesquisadores e sem experiência na administração de um } \\
\text { negócio, principalmente na comercialização. } \\
\text { Concentravam as vendas em poucos clientes que contratavam os } \\
\text { serviços devido à fiscalização que sofriam. } \\
\text { Redução da fiscalização de órgãos reguladores como ANVISA que } \\
\text { diminuiu a demanda das análises por parte dos clientes. }\end{array}$ & $\begin{array}{c}\text { Em } 2015 \text { ocorreram mudanças no quadro societário da E5. Novos sócios } \\
\text { com mais experiência em gestão entraram no negócio. } \\
\text { A redução nas fiscalizações é um fator externo, não cabendo à empresa } \\
\text { nenhuma ação específica para esse caso, a não ser mudar o foco de } \\
\text { atuação, que é o que está fazendo. }\end{array}$ \\
\hline Empresa 6 & $\begin{array}{l}\text { Conquistar a confiança dos primeiros clientes (pesquisadores - } \\
\text { usuários dos softwares desenvolvidos pela empresa). Venda pessoal, } \\
\text { feita por um dos sócios às Fundações das Universidades limita o } \\
\text { crescimento. } \\
\text { Modelo de Negócio com contratações por projetos dava instabilidade } \\
\text { ao negócio. }\end{array}$ & $\begin{array}{c}\text { Ampliavam a Rede de Contato de clientes. Os primeiros clientes indicavam } \\
\text { outros e o marketing boca-a-boca minimizava a desconfiança. Diminuíram } \\
\text { o foco no desenvolvimento de novos sistemas complexos e passaram a } \\
\text { vender softwares prontos, chamados de "prateleira". Modificaram o } \\
\text { Modelo de Negócio objetivando obter faturamento recorrente para dar mais } \\
\text { estabilidade ao negócio. Tal mudança foi possível após a decisão de vender } \\
\text { produtos e serviços de forma conjunta. }\end{array}$ \\
\hline
\end{tabular}

Organizadores:

- fov eaesp

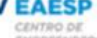




\begin{tabular}{|c|c|c|}
\hline Empresa & $\begin{array}{l}\text { Problemas: Limitações, Dificuldades e Barreiras enfrentadas na } \\
\text { comercialização }\end{array}$ & $\begin{array}{c}\text { Soluções Aplicadas: Atividades e Práticas de Comercialização } \\
\text { adotadas }\end{array}$ \\
\hline Empresa 7 & $\begin{array}{l}\text { Entendimento das demandas específicas apresentadas pelos primeiros } \\
\text { clientes, pois a empresa estava desenvolvendo o software e não tinha } \\
\text { conhecimento de como resolver aquele problema apresentado pelo } \\
\text { cliente. } \\
\text { Venda pessoal feita pelo próprio sócio no início das atividades era } \\
\text { eficiente, mas limitava o crescimento do negócio. }\end{array}$ & $\begin{array}{l}\text { Resolver a demanda de um cliente melhorava o software e isso era passado } \\
\text { para outros clientes como melhorias do sistema, sem custos adicionais. } \\
\text { Ampliavam a rede de contato de clientes pelas indicações. } \\
\text { Passaram a delegar as atividades que eram restritas aos sócios. Criaram um } \\
\text { setor comercial com três pessoas atuando da prospecção à conclusão das } \\
\text { vendas. }\end{array}$ \\
\hline Empresa 9 & $\begin{array}{c}\text { O fato das vendas serem feitas pelos próprios sócios gerou um } \\
\text { acúmulo de funções e atividades e as receitas começaram a estagnar. } \\
\text { Adquirir a confiança dos clientes, tantos dos primeiros como dos } \\
\text { atuais, quando lançam algum software novo. Concorrência desleal. } \\
\text { Precificação dos projetos/serviços. }\end{array}$ & $\begin{array}{l}\text { Faziam parcerias com professores da UFV o que aumentava a credibilidade } \\
\text { da empresa. Não entravam na disputa por preços com a concorrência. } \\
\text { Criaram um setor comercial para ajudar na elaboração das propostas e } \\
\text { minimizar a dependência dos sócios na comercialização. }\end{array}$ \\
\hline $\begin{array}{l}\text { Empresa } \\
10\end{array}$ & $\begin{array}{l}\text { A falta de recursos financeiros e a falta de tempo em função de todas } \\
\text { as atividades comerciais serem feitas pelo próprio sócio limitou o } \\
\text { crescimento do negócio. }\end{array}$ & $\begin{array}{l}\text { Quando era falta de recursos financeiros, recorriam a empréstimos. Quanto } \\
\text { à questão da falta de tempo, procuravam otimizar as atividades. }\end{array}$ \\
\hline $\begin{array}{l}\text { Empresa } \\
\quad 11\end{array}$ & $\begin{array}{l}\text { Sócios eram pesquisadores e sem experiência na administração de um } \\
\text { negócio, principalmente na comercialização. } \\
\text { Ausência de pessoas com "espírito empreendedor" e visão empresarial. } \\
\text { Excesso de burocracia nas autorizações de órgãos fiscalizadores. }\end{array}$ & $\begin{array}{c}\text { Ainda não encontraram soluções para os problemas de comercialização. A } \\
\text { empresa permanece com faturamento inferior a R } \$ 10.000,00 \text { por mês. } \\
\text { A partir de } 2016 \text { iniciaram uma ação de marketing digital e estão } \\
\text { percebendo um crescimento no faturamento. }\end{array}$ \\
\hline \multirow[t]{2}{*}{$\begin{array}{l}\text { Empresa } \\
12\end{array}$} & $\begin{array}{l}\text { Resistência dos clientes de usar os sistemas. Alta rotatividade das } \\
\text { pessoas do comercial. Concorrência. } \\
\text { Falta de recursos financeiros para estruturar e manter o setor } \\
\text { comercial, pois as ações para buscar novos clientes estão estagnadas. }\end{array}$ & $\begin{array}{l}\text { A comercialização dos softwares é feita por nutricionistas com } \\
\text { conhecimento técnico na área. Rede de contato com clientes e parcerias } \\
\text { faculdades da área de atuação da empresa. } \\
\text { Uso do Marketing Digital (Google e fan Page) para alavancar as vendas. }\end{array}$ \\
\hline & $\begin{array}{c}\text { A Precificação dos primeiros projetos era feita de forma equivocada. } \\
\text { As vendas e a prestação de serviços eram feitas pelo sócio entrevistado } \\
\text { o que o sobrecarrega e limitava o crescimento do negócio. }\end{array}$ & $\begin{array}{l}\text { Mudaram o Modelo de Negócio, deixando de prospectar os produtores } \\
\text { rurais diretamente e passando a prospectar os laticínios para os quais os } \\
\text { produtores são fornecedores. }\end{array}$ \\
\hline
\end{tabular}

Organizadores:

- fov eaesp EAESP

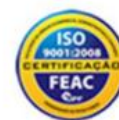

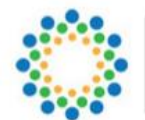

aneGePE

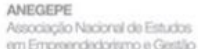

Realizadores:
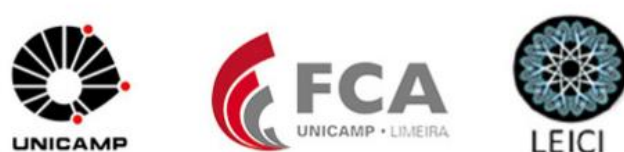


\begin{tabular}{|l|c|r|}
\hline XEGEPE & $\begin{array}{r}\text { Encontro de Estudos sobre Empreendedorismo } \\
\text { e Gestão de Pequenas Empresas }\end{array}$ & $\begin{array}{r}\text { São Paulo/SP } \\
04 \text { a } 06 \text { de julho } \\
\text { de } 2018\end{array}$ \\
\hline
\end{tabular}

Empresa
13

Fonte: Dados da Pesquisa 


\section{Conclusões}

Nesse estudo procurou-se respostas para as seguintes perguntas $\otimes 1)$ Quais as principais dificuldades as PEBTs enfrentam na hora de oferecer seus novos produtos e serviços ao mercado? Que razões estão na origem dessas dificuldades?

Um dos principais problemas evidenciados no estudo está na base de competências em gestão e comercialização dos sócios das PEBTs, pois, muitas vezes, a empresa é criada por empreendedores técnicos (empreendedor acadêmico) com uma forte orientação tecnológica e fraca orientação mercadológica e empresarial. Esse problema pode ser minimizado à medida que os empreendedores utilizem abordagens mais técnicas em suas negociações, fazendo uma venda mais consultiva, dando mais ênfase ao serviço e benefícios da inovação e menos ao produto em si.

Outro problema refere-se à escassez de financiamento desses empreendimentos e precisa ser resolvido, pois é necessário investir durante um longo período em pesquisa e esperar por resultados de comercialização de longo prazo. A ausência de recursos financeiros é um obstáculo à realização das atividades de comercialização e à contratação de recursos humanos com experiência, e, consequentemente limita o crescimento das vendas.

Foi possível identificar uma excessiva concentração das atividades de venda e suporte aos clientes unicamente nos sócios, que assumem essas atividades quase que exclusivamente através da "Venda Pessoal".

Se, por um lado, essa prática se mostrou eficiente, pois as vendas aconteciam quando eram feitas dessa forma, por outro lado, sobrecarregou os empreendedores e limitou o crescimento do negócio, pois à medida que o número de clientes crescia, crescia também a área de atuação e a demanda por suporte e pós-venda.

As principais soluções desenvolvidas por algumas empresas para minimizar os problemas de comercialização foram (1) ativar, ampliar, acumular e manter sua Rede de Comercialização, por meio das indicações de clientes (marketing boca-a-boca) e das indicações feitas em função da rede de contato dos empreendedores (professores e pesquisadores da UFV) e (2) usar ferramentas de marketing digital (internet, e-mail marketing, Google, redes sociais).

Cabe destacar que essas soluções não requerem recursos financeiros elevados e os resultados desse estudo apontam para sua efetividade.

Portanto, é possível inferir que as PEBTs passam por algumas dificuldades ao comercializarem suas inovações por duas razões principais: (1) excessiva concentração dos esforços de venda nos empreendedores e contatos com os clientes realizados tardiamente, (2) não desenvolveram e construíram competência em comercialização, especificamente identificando um nicho de mercado e considerando os clientes iniciais e potenciais para poder desenvolver um modelo de negócio viável, usando suas redes de contatos efetivamente. 
Os resultados dessa pesquisa oferecem uma contribuição teórica à medida que seus resultados agregam aos achados já consagrados e difundidos na literatura sobre o tema. Oferecem também uma contribuição efetiva aos empreendedores e gestores de PEBTs. As práticas de comercialização e as soluções adotadas para superar suas dificuldades são exemplos que ajudam na condução dos negócios e no crescimento das vendas.

Agradecimentos: Os autores agradecem à CAPES - Coordenação de Aperfeiçoamento de Pessoal de Nível Superior, fundação do Ministério da Educação (MEC) e ao Centro Federal de Educação Tecnológica - CEFET-MG, pelo apoio concedido para a realização dessa pesquisa.

\section{REFERÊNCIAS BIBLIOGRÁFICAS}

AARIKKA-STENROOS, L.; SANDBERG, B. (2012) From new-product development to commercialization through networks. Journal of Business Research 65 198-206.

ADAMS, R., BESSANT, J., AND PHELPS, R. (2006). "Innovation Management Measurement: A Review." International Journal of Management Reviews 8(1): 21-47.

ABES - Associação Brasileira das Empresas de Software, Mercado Brasileiro de Software: panorama e tendências, 2015 = Brazilian Software Market: scenario and trends, 2015 [versão para o inglês: Anselmo Gentile] - 1a . ed. - São Paulo: ABES - Associação Brasileira das Empresas de Software, 2015.

ANDRADE JUNIOR, P. P. de (2012).; The Brazilian Experience In Overcoming Difficulties of Technology-Based Companies in Incubators. Journal of Technology Management \& Innovation, v. 7, p. 161-171, 2012.

ANPROTEC, Estudo, Análise e Proposições sobre as Incubadoras de Empresas no Brasil - relatório técnico / Associação Nacional de Entidades Promotoras de Empreendimentos Inovadores. Ministério da Ciência, Tecnologia e Inovação. - Brasília: ANPROTEC, 2012.

CHEN, Chung-Jen, (2009) Technology commercialization, incubator and venture capital, and new venture performance, Journal of Business Research 62 93-103.

CHIESA, V.; FRATTINI, F. (2011) Commercializing technological innovation: learning from failures in high-tech markets, Journal of Product Innovation Management, Vol. 28 No. 4, pp. 437-454.

CHOI, H.; KIM, S.; LEE, J. (2010) Role of network structure and network effects in diffusion of innovations. Industrial Marketing Management 39. 170-177

COSTA, C.; FONTES, M.; HEITOR, M.V. (2004) A methodological approach to the marketing process in the biotechnology-based companies. Industrial Marketing Management, 33.403 - 418.

D’AVINO, M.; DE SIMONE, V.; IANNUCCI, M.; SCHIRALDI, M. M. (2015) Guidelines for eStartup Promotion Strategy. Journal of Technology Management \& Innovation, Volume 10, Issue 1.

DE JONG, J.; MARSILI, O. (2006) The fruit flies of innovations: A taxonomy of innovative small firms. Research Policy 35. 213-229 
DATTA, A.; REED, R.; JESSUP, L. (2013) Comercialization of innovations: an overarching framework and research agenda. Vol. American Journal of Business 28 No. 2, pp. 147-191

FARIA, A. F. de. (2015). Estudo, análise e proposições sobre as incubadoras de empresas de Minas Gerais / Adriana Ferreira de Faria, Marcos Fernandes de Castro Rodrigues, Wagner Rogério Ferreira Pinheiro. - Viçosa, MG : Centev, 2015. 124 p. : il. (algumas color.) ISBN: 978-85-65798-01-3

FORSMAN, H. (2011). Innovation capacity and innovation development in small enterprises. A comparison between the manufacturing and service sectors. Research Policy 40 (2011) 739-750

EISENHARDT, K. M.; GRAEBNER, M. E. (2007). Theory building from cases: Opportunities and challenges. Academy of Management Journal, 50, 1: 25-32.

FREEL, M S. (2005). Patterns of innovation and skills in small firms. Technovation 25. 123-134

GANS, J. S.; STERN, S. (2003) The product market and the market for "ideas": commercialization strategies for technology entrepreneurs. Research Policy 32. 333-350

GIL, A. C. (2006) Métodos e Técnicas de Pesquisa Social. 5.ed. São Paulo: Atlas, 2006.

HANG DO, (2014). Thuy. Determinants of Innovation Commercialization Management and Anticipated Returns: An Exploratory Typology of SMEs. International Journal of Innovation and Technology Management Vol. 11, No. 6. 1450042 (20 pages)

HINDLE, K.; YENCKEN, J. (2004). Public research commercialisation, entrepreneurship and new technology based firms: an integrated model. Technovation 24 793-803

KAJANUS, M.; HEINOEN, M.; ESLELINEN, T.; PELLIKKA, J. (2011). Callenges in Commercialisation Processess of Product Innovation SMEs. (2011). EBRF conference (Research Forum to Understand Business in Knowledge Society) Disponível em < http://www.ebrf.fi/ file/43891/EBRF11 1005.pdf> Acesso em 19/11/14.

LIAO, T; RICE J. (2010). Innovation investments, market engagement and financial performance: A study among Australian manufacturing SMEs. Research Policy 39 (2010) 117-125

MAZZAROL, T.; REBOUD, S.; SOUTAR G. (2011) Innovation Management and Commercialisation in Small Firms: A Study of OECD Countries. 56th Annual ICSB World Conference. Disponível em $<$ http://www.cemi.com.au/sites/all/publications/Mazzarol\%2C\%20Reboud\%20and\%20Soutar\%20ICS B\%202011.pdf> Acesso em 19/11/14.

MEIRA, S. L. (2013). Novos Negócios Inovadores de Crescimento Empreendedor no Brasil. Rio de Janeiro. Casa da Palavra.

MOORE, G. (2002). Crossing the Chasm. Harper Business, New York.

NUNES, P. M.; SERRASQUEIRO, Z.; LEITÃO, J. (2012). Is there a linear relationship between R\&D intensity and growth? Empirical evidence of non-high-tech vs. high-tech SMEs. Research Policy 41.3653 
OLIVEIRA, R. S.; SOUZA, A. C..; FARIA, A. F. (2009). in: Histórias de Sucesso Empresas Graduadas das Incubadoras Mineiras 2, SEBRAE Minas Belo Horizonte, Minas Gerais, 2009.

PARTANEN, J.; CHETTY, S. K., RAJALA, R. (2014) Innovation Types and Network Relationships. Entrepreneurship Theory and Practice, September.

PELLIKKA, J.; VIRTANEN, M. (2009) Problems of commercialisation in Small Technology-Based Firms. Int. J. Entrepreneurship and Innovation Management, Vol. 9, No. 3, pp.267-284.

PELLIKKA, J.; PELLIKKA, J. (2011). Are commercialisation process models beneficial for small technology firms? Int. J. Technology Transfer and Commercialisation, Vol. 10, Nos. 3/4, pp.229-246.

PELLIKKA, J.; LAURONEN. (2007). Fostering commercialisation of innovation in small high technology firms. International Journal Technoentrepreneurship, Vol. 1, No. 1

PELLIKKA, J.; MALINEN P. (2015). Fostering Business Growth and Commercialisation Processes in Small High Technology Firms. International Journal. Business Environment, Vol. 7, No. 1.

PELLIKKA, J.; MALINEN P. (2014). Business Models in the Commercialization Processes of Innovation Among Small High-technology Firms. International Journal of Innovation and Technology Management Vol. 11, No. 2 (2014) 1450007.

PELLIKKA, J. (2014). Commercialization Process of Innovation in Small High-Technology Firms Theoretical Review. In: Handbook Of Research On Techno-Entrepreneurship, Second Edition How Technology and Entrepreneurship are Shaping the Development of Industries and Companies François Thérin Edited by François Thérin, Curtin University Sarawak, Malaysia 2014400 pp Hardback 9781 781951811 - ebook isbn 9781781951828.

PELLIKKA, J. MALINEN, P. (2011). Developing Commercialisation of Innovation in High Technology Industries - Regional Perspective. Small Business Advancement National Center - (2011). Disponível em < http://sbaer.uca.edu/research/icsb/2011/151.pdf> Acesso em 19/11/14.

PLANO DE NEGÓCIO DA EMPRESA 3 (2007). Submetido ao Processo Seletivo da Incubadora de Base Tecnológica do CENTEV - Universidade Federal de Viçosa.

SANTOS, D.T.; PINHO, M. (2010). Análise do crescimento das empresas de base tecnológica no Brasil. Produção, v. 20, n. 2, abr./jun. 2010, p. 214-223

YIN, R. K. (2010) Estudo de Caso: planejamento e métodos. Trad. Daniel Grassi. 4. ${ }^{a}$ ed. Porto Alegre: Bookman.

ZAHRA, S. A. AND NIELSEN, A. P. (2002), Sources of capabilities, integration and technology commercialization. Strategic Management Journal, 23(5), 377-398.

WONGLIMPIYARAT, J.; YUBERK, N. (2005). In support of innovation management and Roger's Innovation Diffusion theory. Government Information Quarterly 22. 411-422

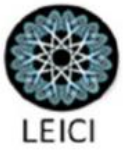

